\title{
Complicações determinadas por placas de cloreto de polivinila (PVC) na estabilização da porção cervical caudal da coluna vertebral de cães ${ }^{1}$
}

\author{
Complications determined by polyvinylchloride (PVC) plates in the stabilization of \\ caudal cervical vertebral column of dogs
}

\author{
Mônica Vicky Bahr Arias² Júlia Maria Matera ${ }^{3}$ \\ Antônio Carlos Faria dos Reis ${ }^{4}$ Nilce Marzolla Ideriha ${ }^{5}$
}

RESUMO

Em 10 cães com peso médio de $14,6 \mathrm{~kg}$, as vértebras cervicais 5 e 6 foram cirurgicamente desestabilizadas através da secção do disco intervertebral $e$, em seguida, estabilizadas com placas ortopédicas confeccionadas com $P V C$ de $2 \mathrm{~mm}$ de espessura, para após 180 dias, proceder-se ao estudo histológico do tecido ósseo e conjuntivo circunvizinho. Constatou-se que o PVC causou alterações ósseas que podem ter favorecido o afrouxamento dos parafusos e a falha do implante. O material induziu ainda à formação de granuloma de corpo estranho e a reações inflamatórias locais que podem ter causado degradação do material implantado. Assim, placas de PVC, apesar de proporcionarem estabilidade $e$ alinhamento da coluna vertebral, não satisfazem a maioria das propriedades necessárias a um biomaterial, não sendo recomendadaa a sua utilização em ortopedia veterinária.

Palavras-chave: cães, cirurgia, afecções da coluna vertebral, cloreto de polivinila.

\section{ABSTRACT}

In ten dogs with an average mean weight of $14,6 \mathrm{~kg}$, the cervical vertebra 5 and 6 were destabilized and fixed with plates of $2 \mathrm{~mm}$ of thickness. The purpose of this work was to verify the effect of orthopedic PVC plates on the internal stabilization of the caudal cervical spine of dogs by studying the occurrence of alterations in the bone tissue and fibrous tissue adjacent to the plate after 180 days of permanence of the material

\begin{abstract}
in the dogs' organism. PVC causes progressive bone alterations, which, in the long term, could promote the loosening of the screws and failure of the implant. It also induces the formation of foreign body granuloma and inflammatory reactions which could cause degradation of the implant. Thus, PVC plates do not satisfy the majority of properties required of a biomaterial, its use not being recommended in veterinary orthopedics.
\end{abstract}

Key words: dogs, surgery, spinal diseases, polyvinylchloride.

\section{INTRODUÇÃO}

O cloreto de polivinila (PVC) é um plástico originado da polimerização do monômero cloreto de vinila, utilizado na manufatura de materiais de uso médico e veterinário, embalagens de cosméticos, encanamentos e caixas d'água, brinquedos de plástico macio para bebês e crianças, filmes para embalar alimentos e frascos para bebidas (TUDURY et al., 1997b; KOOP \& JUBERG, 1999). Muitos destes produtos têm incorporados em sua composição plastificantes (ZHAO \& COURTNEY, 1999), lubrificantes, antioxidantes, modificadores de impacto, pigmentos, melhoradores de brilho, recheios, antichama e estabilizantes para melhorar a

${ }^{1}$ Parte da tese apresentada pelo primeiro autor como requisito parcial para obtenção do título de doutor junto ao Departamento de Cirurgia, Faculdade de Medicina Veterinária e Zootecnia da USP.

${ }^{2}$ Médico veterinário, Professor Adjunto, Departamento de Clínicas Veterinárias, CCA, Universidade Estadual de Londrina, Rodovia Celso Garcia Cid, CP6001, 86051-990, Londrina, PR. Email:vicky@uel.br Autor para correspondência.

${ }^{3}$ Médico Veterinário, Professora Titular, Faculdade de Medicina Veterinária e Zootecnia da USP

${ }^{4}$ Médico Veterinário, Professor Adjunto, Departamento de Medicina Veterinária Preventiva, CCA, UEL

${ }^{5}$ Biólogo, Professora Associada, Departamento de Histologia, CCB, Universidade Estadual de Londrina 
apresentação e as propriedades físicas dos produtos (GOTTESMAN \& GOODMAN, 1985; TUDURY, 1996). Essas substâncias, principalmente os plastificantes e o próprio cloreto de vinila, se liberadas no organismo, poderiam trazer riscos à saúde dos seres humanos e animais (KOOP \& JUBERG, 1999). Essa liberação depende da concentração da substância, da afinidade química com meio que o envolve, da temperatura e da umidade (GOULAS et al., 1998).

ALMEIDA \& REZENDE (1990) e RODRIGUEZ et al. (1993) utilizaram placas plásticas confeccionadas a partir de tubos de PVC Tigre $^{\circledR}$ na imobilização interna das fraturas de ossos longos de cães, obtendo bons resultados cirúrgicos e econômicos. Entretanto, no osso cortical sob o implante, RODRIGUEZ ALVAREZ (1990) constatou reação periosteal e áreas de necrose, que podem ter sido causadas pela compressão com conseqüente interferência na circulação periosteal. O mesmo tipo de placa aplicado por TUDURY (1996) e TUDURY et al. (1997 a e b) nos processos espinhosos e corpos vertebrais da coluna lombar desestabilizada de cães, durante 45 dias, proporcionou boa estabilidade e alinhamento da coluna vertebral, não alterando o hemograma, a urinálise, a concentração de bilirrubina, a albumina, a alanina aminotransferase, a creatinina, ou a histologia renal e hepática. Ocorreram, no entanto, alterações subclínicas como reação inflamatória granulomatosa, alterações vasculares no tecido fibroso circunvizinho à placa e lesões ósseas como osteonecrose, osteoporose e osteopenia (TUDURY, 1996). GALVÃO et al. (1999a), após aplicar placas de aço e de PVC de $2 \mathrm{~mm}$ de espessura ao corpo mandibular osteotomizado de cães por quatro meses, constataram a consolidação da linha de osteotomia, ocorrendo entretanto osteonecrose com os dois tipos de placas. Segundo os autores, estas alterações foram decorres da toxicidade do material, isquemia por pressão do PVC, efeito de proteção ao estresse fisiológico e do afastamento do periósteo. No tecido conjuntivo ao redor da placa, havia reação inflamatória intensa, sugerindo que mecanismos tóxicos e antigênicos pudessem estar envolvidos neste processo (GALVÃO et al., 1999b). Já placas de PVC, empregadas por MACIEL et al. (1999) na reparação óssea do fêmur de cães jovens, também por 45 dias, não causaram alterações histológicas em osso, fígado, baço, rim e linfonodos, nem hematológicas e de bioquímica sérica. As causas das diferentes reações aos diversos tipos de implantes ainda são obscuras, porém, segundo JOHNSON \& SCHMIDT (1977), isto pode estar relacionado não ao polímero, mas ao tipo de plastificante, estabilizante e outros aditivos.
Segundo TANG \& EATON (1995), o uso de implantes requer que o cirurgião conheça os seus efeitos na interface implante-hospedeiro, pois todos os biomateriais, mesmo os considerados inertes, atóxicos e não imunogênicos, desencadeiam uma seqüência idêntica de eventos, com variações na intensidade da mesma. Estes fatos justificam a procura incessante por biomateriais que cumpram os vários requisitos clínicos, mecânicos e econômicos tão necessários na Medicina Veterinária. Assim, o objetivo deste trabalho foi verificar a eficiência do PVC como biomaterial para confecção de placas ortopédicas na fixação das vértebras cervicais 5 e 6 , desestabilizadas pela secção do disco intervertebral, estudando-se os efeitos do plástico no tecido ósseo e conjuntivo circunvizinho após seis meses de permanência do material no organismo.

\section{MATERIAL E MÉTODO}

Para colocação da placa na coluna cervical, utilizaram-se 10 cães adultos sem raça definida, adultos e com peso médio de 14,6kg. Após exame clínico e neurológico, imunoprofilaxia ${ }^{a}$ e

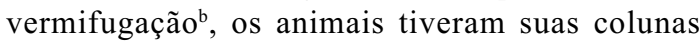
vertebrais cervicais radiografadas para determinação do comprimento das placas, que foram confeccionadas a partir de tubos de PVC-Tigre ${ }^{c}$ branco, com 9,5cm de diâmetro e espessura de $2 \mathrm{~mm}$, seguindo técnica de ALMEIDA \& REZENDE (1990), lavadas e preparadas segundo TUDURY (1996) e esterilizadas em autoclave a $121^{\circ} \mathrm{C}$ (ARIAS, 2001). Após a aplicação de acetilpromazina $^{\mathrm{d}}$ como medicação pré-anestésica e pentobarbital sódico ${ }^{\mathrm{e}}$ como anestésico geral, realizouse acesso cirúrgico para exposição da face ventral dos corpos vertebrais. A junção intervertebral C5-C6 foi desestabilizada por meio da secção do disco intervertebral com lâmina de bisturi no 11 . A placa com quatro orifícios foi colocada ventralmente aos corpos vertebrais, de modo que houvesse dois orifícios sobre cada vértebra e, em seguida, após confecção dos respectivos orifícios ósseos com broca $2,0 \mathrm{~mm}$, fixadas com parafusos ortopédicos do tipo cortical de $2,7 \mathrm{~mm}$. Após testar a estabilidade da fixação, os tecidos expostos foram lavados com solução de $\mathrm{NaCl} 0,9 \%$ estéril, procedendo-se então à síntese dos planos cirúrgicos com náilon 2-0. Após realizar-se curativo do ferimento com polivinilpirrolidona, procedeu-se à colocação de imobilização externa e realização de radiografias da região operada. Antibioticoterapia com enrofloxacina ${ }^{\mathrm{f}}$ foi realizada no momento da indução anestésica e mantida por sete dias. Utilizou-se ainda dipirona $^{\mathrm{g}}$ injetável, a cada 8 horas, durante 3 dias. 
Quarenta e cinco dias após a realização do ato cirúrgico, foram realizadas novas radiografias laterais e ventro-dorsais.

Os cães foram examinados quinzenalmente e no $180^{\circ}$ dia, após realização de exame clínico, foram submetidos à eutanásia com cloreto de potássio a $15 \%$ sob anestesia geral, utilizando-se o mesmo protocolo utilizado no ato cirúrgico. O conjunto vertebral C4-C5-C6 foi dissecado para verificar, através de movimentos de flexão e extensão, a estabilidade vertebral. Os mesmos movimentos foram realizados após a retirada dos implantes. A estabilidade foi classificada segundo a seguinte graduação proposta por SWAIM (1975): grau 1- vértebras C5-C6 estáveis, à manipulação não havia movimentação, as vértebras estavam fusionadas e imóveis como uma unidade; grau 2 - vértebras C5-C6 levemente instáveis, com movimentos perceptíveis à manipulação digital; grau 3 - vértebras C5-C6 moderadamente instáveis, movimento entre elas igual ao movimento das vértebras adjacentes, não estabilizadas com implante; grau 4 - vértebras C5-C6 instáveis, com movimento entre elas maior que o movimento entre as vértebras adjacentes não estabilizadas com implante. Verificou-se, além da estabilidade das vértebras, o afrouxamento dos parafusos, o estado das placas e a penetração de parafusos no canal vertebral. Os corpos vertebrais de $\mathrm{C} 5$ e $\mathrm{C} 6$ foram seccionados em fatias e fixados em formol e também em Bouin, sendo posteriormente descalcificados em solução contendo $250 \mathrm{ml}$ de ácido fórmico a $90 \%, 100$ gramas de citrato de sódio e $750 \mathrm{ml}$ de água destilada. Após a descalcificação, as peças ósseas, assim como a cápsula fibrosa que envolvia as placas, foram processadas pela técnica rotineira de inclusão em parafina e coradas com hematoxilina-eosina, para serem analisadas morfologicamente com o uso de microscopia óptica de luzcomum.

\section{RESULTADOS}

Após a realização da cirurgia, nenhum cão exibiu, no pós-operatório, imediato sinais clínicos ou neurológicos compatíveis com trauma da medula espinhal ou falha do implante. Nos exames radiográficos realizados no pós- operatório imediato e aos 45 dias, as vértebras estavam normais e alinhadas, havendo, porém, aos 45 dias a migração parcial de 18 parafusos. À necropsia, as placas de PVC estavam firmemente envolvidas por uma cápsula fibrosa, com aproximadamente $2 \mathrm{~mm}$ de espessura. Após a retirada deste tecido, constatou-se que a estabilidade com a placa foi total nos 10 cães. Após a retirada da placa, constatou-se estabilidade grau $1 \mathrm{em}$ sete animais e grau
2 em três animais. Não foi observada secreção ou coleção líquida entre a placa e os corpos vertebrais ou entre a placa e a cápsula fibrosa, porém em quatro placas havia alteração na cor, que adquiriu um aspecto amarelado na face em contato com o corpo da vértebra e região correspondente ao disco intervertebral. Verificou-se que uma placa, próxima ao orifício do $3^{\circ}$ parafuso, estava rompida, o que foi observado somente após a retirada do tecido fibroso. Havia ainda a presença de 13 parafusos frouxos, mas que não sofreram migração.

À histologia óssea dos 10 animais que receberam a placa, constatara-se pequenos focos de osteonecrose (Figura 1A ), nas regiões trabecular e cortical, maior porosidade na região cortical sob o implante, adelgaçamento ou espessamento das trabéculas ósseas com estreitamento dos espaços da cavidade medular (Fig. 1A). As lesões observadas na medula óssea consistiram de hipoplasia medular e mielofibrose, alterações observadas em todos os animais (Figura 1B). Constatou-se ainda metaplasia condróide no interior da medula óssea, com presença de células cartilaginosas atípicas respeitando os limites trabeculares (Figura 1A e 1B). Todos os animais apresentaram osteoblastopenia e até ausência destas células na região endósteo-trabecular, principalmente nas cavidades medulares hipoplásicas (Figura 1B) Observou-se, ainda, metaplasia condróide de algumas trabéculas ósseas, metaplasia condróide do tecido conjuntivo sob a placa, áreas de reabsorção óssea na área de transição entre a cortical e o tecido conjuntivo sob a placa, hemorragia dentro de várias lacunas, além de proliferação de tecido conjuntivo dentro do osso, com congestão dos vasos no interior deste tecido, vasos congestos contendo células inflamatórias e em vários cortes a presença de restos ósseos e necrosados no interior dos tecidos conjuntivo e ósseo (Tabela 1).

$O$ tecido de granulação que envolvia as placas apresentava no conjuntivo mais próximo às mesmas, celularidade difusa, havendo neoformações vasculares e infiltrado inflamatório mononuclear, com predomínio de macrófagos, linfócitos e alguns plasmócitos ao redor dos vasos. Já aquele mais distante era mais organizado, espesso e pouco celular, com muitas fibras colágenas maduras, havendo núcleos de fibrócitos alinhados (Figura 2A e 2B). Nesta porção detectaram-se alguns focos de reação inflamatória, ao redor de vasos neoformados, também com infiltrado inflamatório com predomínio de células mononucleares, principalmente macrófagos e linfócitos (Figura 2A ). Foram observados restos de PVC no interior do tecido conjuntivo, havendo, em alguns casos, envolvimento deste material por macrófagos e fibroblastos e o início da formação de células gigantes.

Ciência Rural, v. 33, n. 6, nov-dez, 2003. 

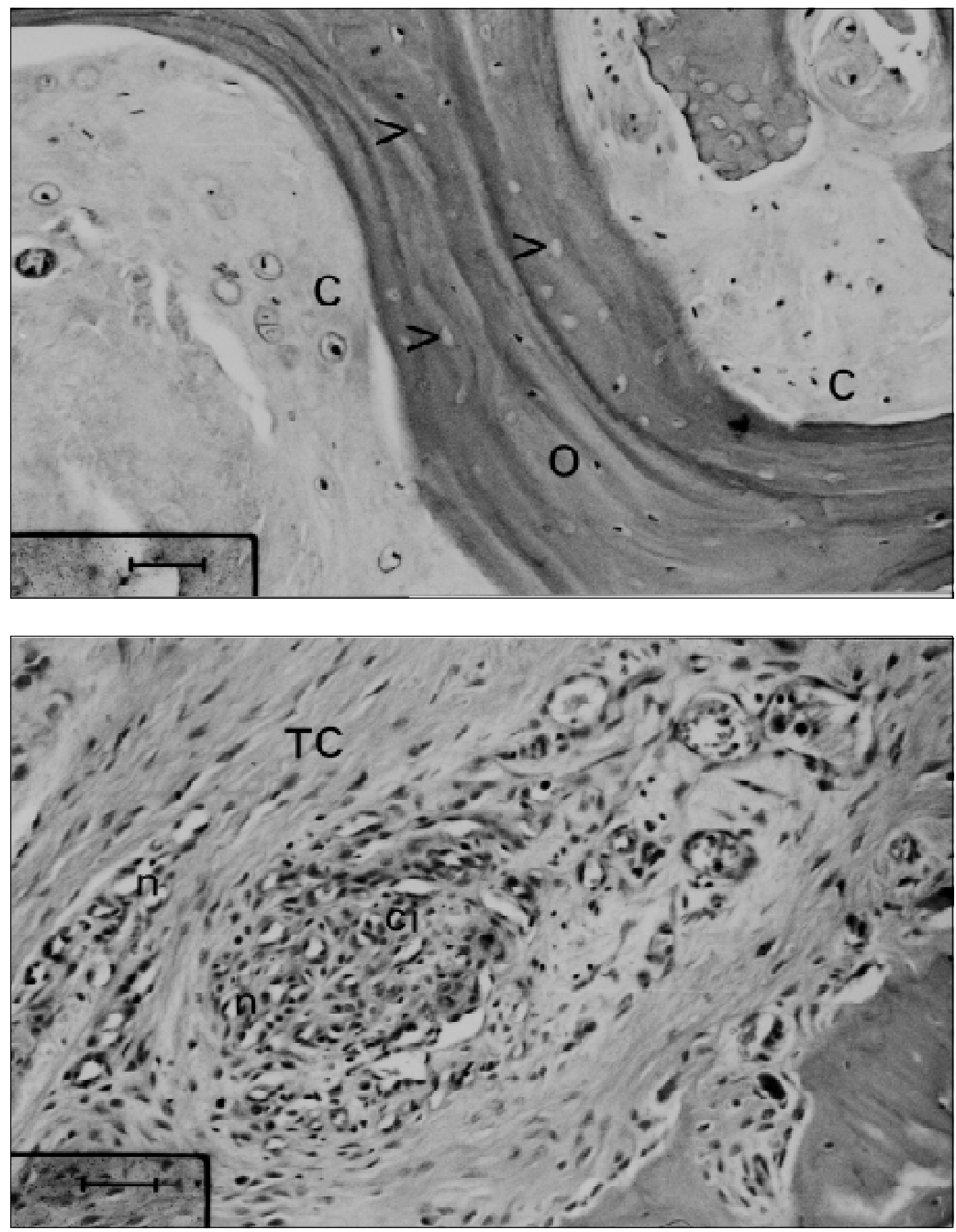

Figura 1 - Alterações em medula óssea e trabéculas ósseas $(\mathrm{O})$ do corpo vertebral em cães submetidos à imobilização da coluna com placas de cloreto de polivinila. A- Metaplasia condróide (C), focos de osteonecrose, caracterizado por lacunas osteocíticas vazias ( $>$ ) (HE, 250X). B- Observa-se hipoplasia da medula óssea (MO) e metaplasia condróide (C) no interior da medula óssea (HE, 125X).

Ciência Rural, v. 33, n. 6, nov-dez, 2003. 

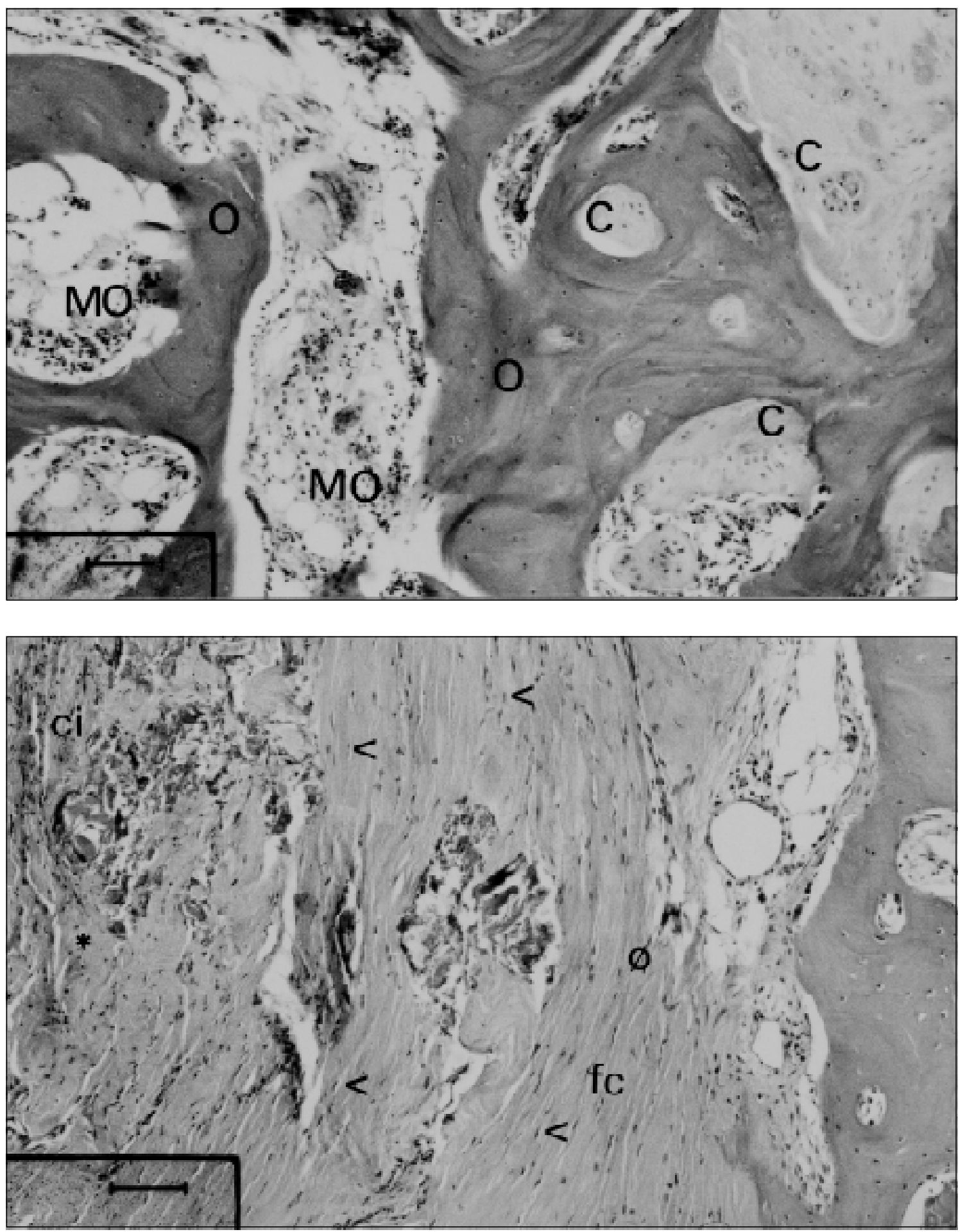

Figura 2 - Tecido conjuntivo (TC) sob a placa de PVC em cães submetidos à imobilização da coluna com placas de cloreto de polivinila.. A: observa-se celularidade difusa e áreas de infiltrado mononuclear perivascular (ci) e neoformações vasculares (n) (HE, 250X). B. Área de transição entre o tecido conjuntivo mais próximo à placa $(*)$ com células inflamatórias (ci) e tecido mais distante da placa (Ø) com fibras colágenas (FC) e fibrócitos (<). (HE, 125X). 
Tabela 1 - Ocorrência e freqüência das alterações histológicas nos corpos das vértebras cervicais de cães submetidos ao implante de placas de cloreto de polivinila por 180 dias. Londrina, 1999.

\begin{tabular}{ll}
\hline Alteração & F \\
\hline Osteonecrose e porosidade cortical sob a placa & 10 \\
Osteoblastopenia & 10 \\
Hipoplasia medular e mielofibrose & 10 \\
Formação de tecido ósseo jovem & 6 \\
Reabsorção de tecido ósseo na cortical em & 6 \\
contato com a placa & \\
Restos de PVC no interior do osso & 6 \\
Restos ósseos e necrosados no interior do tecido & 5 \\
conjuntivo e ósseo & \\
Espessamento das trabéculas & 5 \\
Necrose no interior da medula óssea & 5 \\
Adelgaçamento das trabéculas & 4 \\
Metaplasia condróide do tecido conjuntivo & 4 \\
Metaplasia condróide da medula óssea & 2 \\
Metaplasia condróide do tecido ósseo & 1 \\
\hline
\end{tabular}

\section{DISCUSSÃO E CONCLUSÕES}

A migração e o afrouxamento dos parafusos constatados neste trabalho, segundo SMITH (1985) e JEFFERY (1995), podem ser decorrentes do uso de parafusos com diâmetro inadequado, uso de furadeira com rotação muito alta, excesso de tensão no parafuso se não houver boa acomodação da placa ou da falta de rosqueamento para introdução do parafuso. Porém, SWAIM (1987) e SEIM III (1990) não recomendavam o rosqueamento dos orifícios dos parafusos corticais, para aplicação de placas plásticas de polivinilideno na coluna cervical de cães com espondilomielopatia. Outros fatores que podem contribuir para o afrouxamento dos parafusos são a constituição das vértebras cervicais, o uso da imobilização externa por pouco tempo e a rejeição do implante. Esta rejeição, segundo SMITH (1985) e GOODMAN et al. (1998), poderia estar relacionada também ao desenvolvimento de uma resposta imune complexa com formação de granuloma de corpo estranho, ocorrendo secreção de citoquinas e enzimas proteolíticas pelos macrófagos ativados após o início do processo, o que levaria à reabsorção óssea, osteólise e perda do implante. As alterações ósseas ocorridas nos corpos vertebrais, como a osteonecrose, a porosidade cortical e o adelgaçamento das trabéculas ósseas, dentre outras, também podem ter colaborado para o processo de migração e afrouxamento dos parafusos. Segundo FETTER et al. (1985), a osteoporose é observada com freqüência em ossos longos imobilizados com placas, pelo efeito de proteção ao estresse, sendo que placas mais rígidas produzem maior grau de osteopenia, a qual resulta do desequilíbrio entre formação e reabsorção em favor da reabsorção. Neste caso, PALMER (1993) ressalta que ocorre diminuição do número de trabéculas, o que não foi constatado neste trabalho. Segundo o mesmo autor, quando há diminuição da formação óssea, observam-se trabéculas em número normal, porém mais finas e fragmentadas, podendo haver evidências de atividade anormal dos osteoblastos, alterações que foram constatadas neste experimento. RODRIGUEZ ALVAREZ (1990) não descreve alterações em osteoblastos aos 30 e 60 dias após a estabilização de ossos longos com placas de PVC. Já TUDURY (1996) e GALVÃO et al. (1999a) constataram que as placas de PVC aplicadas na coluna lombar e na mandíbula também ocasionaram osteoblastopenia, mas com incidência menor do que a observada neste experimento. Porém nem RISCHEN et al. (1987), que utilizaram placas de polivinilideno no processo espinhoso lombar de cães por 12 semanas, nem WHEELER et al. (1999), que aplicaram placas de polipropileno em ossos longos e curtos de cães por até 12 meses, observaram alterações em osteoblastos, osteócitos e canais osteônicos ou osteonecrose. Como neste trabalho havia osteoblastopenia em todos os animais que receberam placa de PVC, deduz-se que algum fator, de caráter progressivo e cumulativo, interferiu na atividade normal destas células. Esta possibilidade é reforçada pelo fato de que trabalhadores das fábricas de PVC, após vários anos de exposição ao produto, podem ser acometidos por acro-osteólise e apresentam nas radiografias, osteólise, fragmentação e perda da cortical nas falanges distais (HAHN et al., 1979).

A incidência de vários focos de metaplasia condróide no interior da medula óssea e do tecido ósseo observada em três animais sugere que algum fator tenha prejudicado a manutenção da tensão de oxigênio, que, segundo HALL (1990), deve ser alta para que ocorra a diferenciação celular e osteogênese. TUREK (1970) explica que, se não houver tensão de oxigênio ou vascularização adequadas, as células osteogênicas se diferenciam em condroblastos e condrócitos, havendo formação de cartilagem, que poderia eventualmente, ser substituída por osso, principalmente se fosse um local propício para a ocorrência do processo de ossificação endocondral. Esta teoria é reforçada pelo fato de que trabalhadores de fábricas de PVC que apresentaram esclerodermia, entre outras alterações, mostraram anormalidades nos capilares da pele, hemorragias e áreas avasculares (MARICQ et al., 1976).

Segundo WILLARD et al. (1989), a mielofibrose é um processo cicatricial que ocorre após a lesão das células da medula óssea e pode ser decorrente de um estímulo nocivo crônico. Para 
WHITE (1996), processos isquêmicos, que interrompam o fluxo sangüíneo na microvasculatura óssea, predispõem principalmente o osso subcondral ao infarto. Este processo poderia ser decorrente, entre outras causas, de trombose, doenças vasculares e do colágeno, trauma, pressão externa, ou do aumento da viscosidade sangüínea, havendo então o comprometimento de artérias, veias ou sinusóides, causando a morte de osteócitos, osteoblastos e células da medula óssea. Acredita-se que o afastamento do periósteo na face ventral dos corpos vertebrais não tenha sido a principal causa da isquemia, embora possa ter colaborado em uma fase inicial, pois, segundo JEFFERY (1995), a irrigação sangüínea dos corpos vertebrais cervicais se origina principalmente da artéria vertebral, que se localiza lateralmente às vértebras. Como todas as vértebras cervicais em contato com a placa de PVC apresentaram mielofibrose, mesmo em locais distantes da região sob a placa, conclui-se que o fator que levou à isquemia e prejudicou a vascularização foi constante, podendo advir de alguma substância liberada pela placa.

A presença de vários vasos congestos e com células inflamatórias no interior da medula óssea; junto às alterações observadas na mesma, osteócitos, osteoblastos e tecido ósseo, incluindo as metaplasias, podem ter sido causadas por isquemia, decorrentes não somente da compressão ou do afastamento do periósteo, como também da obstrução da microvasculatura, devido à congestão venosa e inflamação, como proposto por TUREK (1970). A vasculite tóxica ou imunomediada, devido à deposição de complexos imunes na parede vascular, tal qual ocorre nos trabalhadores das fábricas de PVC com acro-osteólise, também poderia alterar o fluxo sangüíneo, segundo MAGNAVITA et al. (1986). WARD et al. (1976) complementam esta explicação propondo que um metabólito do cloreto de vinila que se liga a proteínas plasmáticas, atuaria como substância antigênica, que por sua vez ativaria o sistema complemento levando à agregação plaquetária, oclusão vascular e isquemia.

Segundo COTRAN et al. (1996), as características do tecido conjuntivo fibroso formado ao redor das placas indicariam uma reação inflamatória do tipo crônica, havendo formação de granuloma do tipo corpo estranho, ou seja, uma reação persistente ao agente agressor, neste caso, a placa de PVC. Esta alteração foi semelhante à descrição da inflamação crônica granulomatosa ao redor de placas Lubra aplicadas por SWAIM et al. (1988) em cães e ratos e da inflamação observada por TUDURY (1996) após aplicação de placas de PVC na coluna lombar de cães, porém em um estágio mais avançado, uma vez que a camada fibrosa observada neste experimento era mais espessa e não possuía tantos plasmócitos. Já GALVÃO et al. (1999), além do infiltrado mononuclear, observaram também polimorfonucleares, atribuindo sua presença à inflamação aguda coexistindo com inflamação crônica, por agudização da reação. Segundo TANG e EATON (1995), a resposta inflamatória crônica pode causar degradação do material implantado através de produtos oxidativos liberados pela associação das células inflamatórias-implante. Isto poderia justificar a alteração da cor da placa observada neste trabalho. Para GRIFFITHS et al. (1996), a degradação do material pode levar à migração de seus componentes aos tecidos vizinhos e à circulação, causando efeitos tóxicos sistêmicos, sendo que para SWAIM et al. (1988), TANG \& EATON (1995) e GRIFFITHS et al. (1996), a inflamação dos tecidos conectivos em indivíduos geneticamente susceptíveis poderia ainda ativar o sistema imune, ocorrendo então complicações como degradação do material, falha do implante nas reações persistentes, reação tecidual local, rejeição, rachaduras do implante, osteólise adjacente às próteses, infecções, acúmulo de fluídos, fístulas e atraso na cicatrização, explicando neste experimento várias das alterações ósseas, inflamatórias e no implante.

A cápsula de tecido fibroso observada neste trabalho foi mais espessa do que a observada por TUDURY (1996) e GALVÃO et al. (1999b), enquanto RODRIGUEZ ALVAREZ (1990) não menciona esta ocorrência 30 dias após a implantação deste material. Esta diferença nos resultados poderia estar relacionada ao tempo de observação, ou a alterações na composição do material, apesar de a marca utilizada ser a mesma. BUTLER et al. (1997), após aplicação de implantes em ratos, demostraram que a espessura do tecido fibroso foi diretamente proporcional ao tempo da aplicação, porém RUBIN et al. (1971) citam que a composição do implante também afeta este resultado. Segundo FORSYTH et al. (1993), o PVC, quando acrescido de uma organotina, substância utilizada para aumentar a resistência dos tubos rígidos ao calor, parece promover durante sua implantação in vivo, resposta inflamatória aguda e posteriormente crônica progressiva muito mais intensas do que o polietileno. Segundo COTRAN et al. (1996), as neoformações vasculares observadas no tecido conjuntivo próximo à placa e também na cápsula fibrosa, são componentes da inflamação crônica. TUDURY (1996) constatou as mesmas alterações e ainda neovascularização com células endoteliais indiferenciadas em um cão. De acordo com MARICQ et al. (1976) e MAGNAVITA et al. (1986), pode

Ciência Rural, v. 33, n. 6, nov-dez, 2003. 
ocorrer proliferação de capilares na pele de trabalhadores das fábricas de $\mathrm{PVC}$ os quais apresentam ou não acro-osteólise, realçando o possível caráter tóxico deste material.

Segundo SMITH (1985), os biomateriais utilizados em cirurgias ortopédicas devem cumprir requisitos clínicos, possuir propriedades mecânicas para sua função de fixação e ser econômicos, em ordem decrescente de importância. Complementando estes requisitos, SERGENT et al. (1993) referem que um material biocompatível não deve se degradar, prejudicando suas propriedades mecânicas, liberar produtos potencialmente lesivos, causar reações imunológicas, inflamatórias, tóxicas ou trombogênicas, alterar as proteínas plasmáticas do hospedeiro nem possuir efeitos carcinogênicos. Neste trabalho, concluiu-se que, apesar de as placas de PVC proporcionarem estabilidade e alinhamento da coluna vertebral, as alterações histológicas observadas mostraram que o material não cumpriu a maioria das propriedades necessárias a um biomaterial, não sendo recomendada a sua utilização em ortopedia veterinária.

\section{AGRADECIMENTOS}

À Universidade Estadual de Londrina e à Capes, pela bolsa concedida, à coordenadoria de Pesquisa e pós graduação da UEL pela aprovação da pesquisa e apoio financeiro e às firmas Socyl Guiomarch, Fort Dodge, Bayer e Virbac, pelo apoio financeiro.

\section{FONTES DE AQUISIÇÃO}

a - Duramune DA2PP + CvK/LCI, Fort Dodge

b - Panacur Plus, Hoecht Roussel Vet.

c - Tigre (Companhia Hansen Industrial), Rua Xavantes, 54 Joinville, SC (89203-210)

d - Acepran 0,2\%, Univet

e - Hypnol 3\%, Fontoveter

f - Flotril 2,5\%, Schering-Plough Veterinária

g - Dipirona injetável, Hipolambor

\section{REFERÊNCIAS BIBLIOGRÁFICAS}

ALMEIDA, A.E.R.F.; REZENDE, C.M.F. Confecção de placas ortopédicas de cloreto de polivinila para redução de fraturas de ossos longos do cão. In: CONGRESSO MINEIRO DE MEDICINA VETERINÁRIA, 1990, Belo Horizonte, MG. Anais... Belo Horizonte: Escola de Veterinária da UFMG, 1990. p.82.

ARIAS, M.V.B. Estudo experimental sobre a estabilização da coluna vertebral cervical caudal de cães com placas de cloreto de polivinila. 2001 . $85 \mathrm{f}$. Tese (Doutorado em Cirurgia) - Curso de Pós-graduação em Cirurgia, Faculdade de Medicina Veterinária e Zootecnia, Universidade de São Paulo.
BUTLER, K. et al. One-year histopathological evaluation of fibrous tissue surrounding TCPL implants using adult rats as a model. Biomedical Science of Instruments, v.33, p.233239, 1997.

COTRAN, R.S.; KUMAR, V.; ROBBINS, S.L. Robbins. Patologia estrutural e funcional. 5. ed. Rio de Janeiro : Guanabara Koogan, 1996. 1277p.

FETTER, A. W.; SIEMERING, G.H.; RISER, W.H Osteoporosis and osteopetrosis. In: NEWTON, C.D.; NUNAMAKER, D.M. Textbook of small animal orthopaedics. Philadelphia : Lippincot, 1985. Cap.55, p.627-629.

FORSYTH, D.S. et al. Speciation of organotin in poly(vinyl chloride) products. Food and Additive Contaminants, v.10, n.5, p. 531-540, 1993.

GALVÃO, S.R. et al. Avaliação das alterações ósseas após emprego de placas ortopédicas de aço inoxidável e placas confeccionadas a partir de policloreto de vinila (PVC) na mandíbula de cães. Veterinária Notícias, v.5, n.1, p.25-33, 1999 a.

GALVÃO, S.R. et al. Avaliação histológica do tecido conjuntivo ao redor de placas ortopédicas confeccionadas a partir de policloreto de vinila comercial (PVC) em cães. Revista Brasileira de Ciência Veterinária, v.6, n.3, p.127-132, 1999 b.

GOODMAN, S.B. et al. In vitro, in vivo, and tissue retrieval studies on particulate debris. Clinical Orthopaedics, v.32, p.25-34, 1998 .

GOTTESMAN, R.T.; GOODMAN, D. Poly(vinyl chloride). In: TESS, RW.; POEHLEIN, G.W. Applied polymer science. 2. ed. Washington : American Chemical Society, 1985. Cap.18, 1341p. p.383-440.

GOULAS, A.E. et al. Effect of high dose electron beam irradiation on the migration of DOA and ATBC plasticizers from food-grade PVC and PVDC/PVC films, respectively, into olive oil. Journal of Food Protetion, v.61, n.6, p.720-724, 1998.

GRIFFITHS, M.M.; LANGONE, J.J.; LIGHFOOTE, M.M. Biomaterials and granulomas. Methods, v.9, n.2, p.295-304, 1996.

HAHN, E. et al. Occupational acroosteolysis in vinyl chloride workers in Israel. Israel Journal of Medical Science, v.15, n.3, p.218-222, 1979.

HALL, B.K. Bone: the osteoblast and osteocyte. New Jersey : The Telford, 1990. 493p.

JEFFERY, N.D. Handbook of small animal spinal surgery. Philadelphia : Saunders, 1995. 236p.

JOHNSON, W.S.; SCHMIDT, R.E. Effects of polyvinyl chloride ingestion by dogs. American Journal of Veterinary Research, v.38, n.11, p.1891-1892, 1977.

KOOP, C.E.; JUBERG, D.R. A scientific evaluation of health effects of two plasticizers used in medical devices and toys: a report from the American Council on Science 
and Health. Capturado em 11 de julho de 1999. Online Disponível em <http://www.medscape.com /Medscape/ GeneralMedicine/journal/1999/v01.n06/mgm0622.koop/ mgm001.html>

MACIEL, F.R.M.C.; ROCHA, A.; LIMA, C.A.P. Efeito da placa de cloreto de polivinila na reparação óssea de cães jovens. Avaliação clínica, laboratorial e histológica. In: CONGRESSO BRASILEIRO DE CLÍNICOS VETERINÁRIOS DE PEQUENOS ANIMAIS, 20., 1999, Águas de Lindóia, SP. Anais... Águas de Lindóia : Anclivepa,1999. p.70.

MAGNAVITA, N. et al. Vasculitic purpura in vinyl chloride disease: a case report. Angiology, v.37, p.382-388, 1986.

MARICQ, H.R. et al. Capillary abnormalities in polyvinyl chloride production workers. Examination by in vivo microscopy. Journal of the American Medical Association, v.235, n.12, p.1368-1371, 1976.

PALMER, N. Bones and joints. In: JUBB, K.V.C.; KENNEDY, P.C.; PALMER, N. Pathology of domestic animals. 4. ed. San Diego, California : Academic, 1993, V.1, cap.1, p.1-181

RISCHEN, C.G.; WILSON, J.W.; SWAIN, C.A. Effect of application of polyvinilidene plates on the dorsal spinous processes of dogs. Veterinary Surgery, v.16, n.4, p.294$298,1987$.

RODRIGUEZ ALVAREZ, L.M. Emprego de placas de cloreto de polivinila na fixação de fratura completa do terço distal do rádio e da ulna no cão novo (Canis familiaris). Estudo experimental. 1990. 44p. Dissertação (Mestrado em Cirurgia Experimental) - Escola de Veterinária, Universidade Federal de Minas Gerais.

RODRIGUEZ, L.M. et al. Emprego de placas plásticas no tratamento de fraturas do rádio e ulna em cães. Arquivos Brasileiros de Medicina Veterinária e Zootecnia, v.43, n.1, p.35-41, 1993.

RUBIN, L.R.; BROMBERG, B.E.; WALDEN, R.H. Long-term human reaction to synthetic plastics. Surgery Gynecology Obstetrics, v.132, p.603-608, 1971.

SEIM III, H.B. Caudocervical apondylomyelopathy in large breed dogs. In: BOJRAB, M.J. Current techniques in small animal surgery. Philadelphia : Lea e Febiger, 1990. 3. ed. Cap. 42, p.579-600.

SERGENT, J.S. et al. Yearbook of rheumatology. St.Louis: Mosby, 1997. 457p.

SMITH, G.K. Orthopaedic biomaterials. In: NEWTON, C.D.; NUNAMAKER, D.M. Textbook of small animal orthopaedics. Philadelphia : Lippincott, 1985. p.120-128.

SWAIM, S.F. Evaluation of four techniques of cervical spinal fixation in dogs. Journal of the American Veterinary Medical Association, v.166,n.11, p.1080-1086, 1975.

SWAIM, S.F. Vertebral and spinal cord surgery. In: OLIVER, J. E.; HOERLEIN, B.F.; MAYHEW, I.G. Veterinary neurology. Philadelphia : Saunders, 1987. Cap.17, p.416-458.

SWAIM, S.F.; RIBBLE, G.A.; WILSON, J.W. Histologic evaluation of response to implantation of polyvinilidene plates in dogs and rats. Veterinary Surgery, v.17, n.5, p.278-281, 1988.

TANG, L.; EATON, J.W. Inflammatory responses to biomaterials. American Journal of Clinical Pathology, v.103, n,4, p.466-471, 1995.

TUDURY, E.A. Imobilização interna da coluna lombar com placas de cloreto de polivinila em cães. Estudo experimental. 1996. 133f. Tese (Doutorado em cirurgia) Escola de Veterinária, Universidade Federal de Minas Gerais.

TUDURY, E.A. et al. Imobilização interna da coluna vertebral com placas de cloreto de Polivinila, em cães - parte I: Resultados clínico-cirúrgicos. Ciência Rural, v.27, n.1, p.93-101, 1997a

TUDURY, E.A. et al. Imobilização interna da coluna vertebral com placas de cloreto de Polivinila, em cães- parte II: resultados anatomopatológicos. Ciência Rural, v.27, n.1, p.103$112,1997 \mathrm{~b}$.

TUREK, S.L. Orthopaedics. principles and their application. 3. ed. Philadelphia : Lippincot, 1970. 1574p.

WARD, A.M. et al. Immunological mechanisms in the pathogenesis of vinyl chloride disease. British Medical Journal, v.1, p.936-938, 1976.

WHEELER, J.T.; GONZALEZ QUINTANA, H. Efectos locales de los implantes de polipripileno en el perro. Observaciones preliminares. Selecciones Veterinarias, v.6, n.5, p.436440, 1999

WILlARD, M.D.; TVEDTEN, H.; TURNWALD, G.H. Small animal clinical diagnosis by laboratory methods. Philadelphia : Saunders, 1989. 380p.

WHITE, M.P. Ischemic bone disease. In: FAVUS, M.J. Primer on the metabolic bone diseases and disorders of mineral metabolism. 3 ed. Philadelphia : Lippincott-Raven, 1996. p.399-402.

ZHAO, X.; COURTNEY, J.M. Influence on blood of plasticized polyvinyl chloride: significance of the plasticizer. Artificial Organs, v.23, n.1, p.104-107, 1999. 